\title{
Avaliação da Aprendizagem no Ensino Superior: Reflexões em uma Perspectiva Andragógica
}

\section{Higher Education Learning Assessment: Reflections from an Andragogical Perspective}

\author{
Osmar Pedrochi Junior*a; Diego Fogaça Carvalho Juniora ; Tattiana Tessye Freitas da Silva ${ }^{\mathrm{b}}$; \\ Nielce Meneguelo Lobo da Costac
}
${ }^{a}$ Unopar, Programa de Pós-Graduação Stricto Sensu em Metodologias para o Ensino de Linguagens e suas Tecnologias. PR, Brasil.

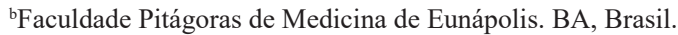
'Universidade Anhanguera de São Paulo, Programa de Pós-Graduação Stricto Sensu em Educação Matemática. SP, Brasil.
*E-mail: osmar.p.junior@kroton.com.br

\begin{abstract}
Resumo
Neste estudo se tem por objetivo refletir a respeito da avaliação da aprendizagem no contexto do Ensino Superior em uma perspectiva andragógica. Cada segmento de ensino apresenta desafios específicos à avaliação da aprendizagem, seja com a função de estimar o rendimento dos estudantes, diagnosticar dificuldades ou intervir e ajustar os processos de ensino e de aprendizagem, a avaliação é sempre um desafio a ser considerado. A avaliação, no olhar andragógico, respeita os conhecimentos anteriores dos estudantes, aprendidos dentro ou fora do particular curso de formação. No Ensino Superior, as experiências dos alunos adultos devem ser levadas em consideração e a eles deve ser dada a chance de estabelecer relações entre as experiências pessoais anteriores e as novas experiências proporcionadas no curso. Nesse sentido, a autoavaliação é importante para a tomada de consciência e por fazer parte da formação profissional. Saber se autoavaliar é o primeiro passo para ser autônomo e é uma característica desejada no mundo do trabalho. A utilização de portfólio para avaliação traz consigo a perspectiva de avaliação individualizada, uma vez que cada portfólio é único e produzido pelo próprio estudante, portanto, influenciado pelas suas experiências e conhecimento individual. Caraterísticas mais citadas na literatura para se ter a avaliação na visão andragógica são os feedbacks e a prévia ciência do aluno quanto aos critérios a serem utilizados no processo avaliativo. Como conclusão se evidenciou a premência em tratar o aluno adulto realmente como o adulto que ele é, uma pessoa que traz com ela uma carga de conhecimento do mundo. Esse é um desafio a ser enfrentado pelos docentes, nos processos de ensino e de aprendizagem, nos quais se inclui a avaliação.
\end{abstract}

Palavras-chave: Ensino Superior. Andragogia. Avaliação. Feedback. Portfólio.

\begin{abstract}
This study aims to reflect on the Higher Education learning assessment from an andragogical perspective. Each teaching segment presents specific challenges to the learning assessment, either with a student's performance estimation function, or diagnosing difficulties or intervening and adjusting teaching and learning processes, assessment is always a challenge to be considered. Assessment, in the andragogical perspective, respects the students' previous knowledge, learned inside or outside the course. In Higher Education, the adult students'experiences must be considered, and to them must be given the chance to establish relationships between previous personal experiences and the new experiences provided by the course. In this sense, self-assessment is important for raising awareness and it is a part of professional training. Knowing how to evaluate oneself is the first step towards being autonomous and is a desired characteristic in the world of work. The use of portfolio for evaluation brings with it the perspective of individualized evaluation, since each portfolio is unique and produced by the student himself or herself, therefore, influenced by his or her experiences and individual knowledge. Themost cited characteristics in the literature, to have the evaluation in an andragogical view, are the feedbacks and the student's previous knowledge regarding the criteria to be used in the assessment process. As a conclusion, there was an urgency to treat the adult student really as the adult he or she is, a person who brings with him or her a load of the world knowledge. This is a challenge to be faced by the teachers, in the teaching and the learning processes, which includes evaluation.
\end{abstract}

Keywords: Higher Education. Andragogy. Assessment. Feedback. Portfolio.

\section{Introdução}

No conjunto de pesquisas referentes às vivências educacionais, um dos objetos de estudo presentes é a avaliação ${ }^{1}$. Concebido de formas variadas e com vivências nem sempre estimulantes, o ato de avaliar é um dos momentos desafiadores do processo de ensino e aprendizagem.

A história das práticas educacionais tem evidenciado que o momento de avaliação da aprendizagem tem se configurado como um momento estressante tanto para quem conduz o processo, o professor, quanto para quem se submete a esse, o estudante $^{2}$. O foco e a energia dispensada para a elaboração,

1 No Brasil, estudos sobre a história da avaliação da aprendizagem têm mostrado tanto os desafios quanto as evoluções desse processo. Sobre isso, podem ser citados trabalhos como: Catani (2017) e Esteban (2012).

2 Ao longo do texto, preferiu-se substituir o termo aluno, por estudante ou aprendente, este último termo usado pela andragogia. A escolha por estudante decorre do fato de que etimologicamente aluno, significa ser sem luz. Entende-se que tal denominação não se alinha àquele que tem e que busca o conhecimento. 
aplicação e correção de uma prova (a forma de avaliação mais usada) pode esgotar emocionalmente os atores envolvidos nessa experiência, sem muitas vezes apresentar como contrapartida dados relevantes para o processo educacional.

No segmento do Ensino Superior, no qual os aprendentes são jovens e adultos, a forma de avaliar o caminhar dos estudantes deve apresentar características que considerem esse particular segmento etário dos aprendizes, especialmente, ao se considerar a importância para a sociedade contemporânea da aprendizagem ao longo de toda a vida.

Diante disso, algumas questões são reforçadas na contemporaneidade: como é possível transformar a experiência de avaliação no Ensino Superior para todos os atores envolvidos? Como fazer da avaliação um momento de aprendizado, sem causar demasiado estresse? De que forma a avaliação pode ser cada vez mais percebida como um meio e não como um fim?

Estudos associados à andragogia podem apontar caminhos que propiciem outras vivências relacionadas à avaliação, no processo de formação profissional dos jovens e dos adultos. Diante disso e olhando a realidade brasileira para a educação, no âmbito do Ensino Superior, se propõe refletir sobre um caminho avaliativo, que possa ser trilhado pelos estudantes, vivenciando a avaliação como parte do aprendizado e pelos professores entendendo a avaliação como uma prática da docência. Nesse sentido, segue-se Zabala (2015), para o qual na prática de ensinar, uma das etapas é a de avaliar a aprendizagem empreendendo diagnósticos sobre os conhecimentos já construídos pelos aprendentes, dando feedbacks sobre suas fragilidades e enganos e, também, sobre acertos e conhecimentos já construídos pelos discentes. Para além disso, no processo avaliativo, o docente obtém devolutivas das suas ações de ensino, de forma a compreender se essas foram capazes de criar oportunidades para a aprendizagem. Assim, a avaliação se presta a auxiliar na correção de caminhos tanto para docentes quanto para aprendentes.

Diante do exposto, este artigo tem por objetivo apresentar reflexões a respeito da avaliação da aprendizagem no contexto do Ensino Superior, em uma perspectiva andragógica.

\section{Desenvolvimento}

Pensar e vivenciar a avaliação para além da aplicação de testes e provas é um exercício que propicia trazer à tona alguns aspectos, que constituem as ideias basilares da andragogia $^{3}$. Antes, no entanto, vale registrar que a palavra andragogia, etimologicamente, vem do grego añer, com a conjugação andr e está associada à arte e à ciência de facilitar a aprendizagem dos adultos (NOGUEIRA, 2004).

Knowles, Helton e Swanson (2011) listam os seguintes princípios da aprendizagem andragógica:

1. necessidade do aprendiz de saber: nesse aspecto, entram em cena os questionamentos que envolvem os porquês, os quês e os como;

2. autoconceito do aprendiz: ciente dos seus questionamentos, parte para os estudos, adotando posturas de autonomia e autoaprendizagem;

3. experiência anterior do aprendiz: que modelos mentais, que ideias rondam o território do conhecimento prévio;

4. prontidão do aprendiz para aprender: determinação em desenvolver um saber sobre algo;

5. orientação do aprendiz para a aprendizagem: saber o porquê está estudando algo e como esse aprendizado pode ser aplicado. Contexto da aprendizagem;

6. motivação para aprender: valor intrínseco ao estudante; o aprender gera para ele uma recompensa pessoal.

Analisando tais aspectos e trazendo-os para o processo de aprendizagem no Ensino Superior se argumenta que para esse estudante, em uma perspectiva andragógica, é necessário: motivação pessoal para o aprendizado e o estudo; consciência da necessidade de seu protagonismo no processo de aprendizagem e reconhecimento pessoal acerca do que o conhecimento pode lhe proporcionar. Para complementar, considerando a possibilidade de existência de um orientador, que apoie o discente nesse processo, no caso, o professor, as atitudes necessárias para implementar a experiência de aprendizagem, são: respeito e reconhecimento pelos saberes prévios do estudante com relação aos temas estudados; inserção desse saber no processo de construção do conhecimento; e construção do conhecimento a partir do ato de compartilhar questionamentos e da busca de saberes para a resolução de problemas. A adoção dessas atitudes pressupõe para o docente uma transformação nas concepções e comportamentos, normalmente adotados, para promover a vivência tradicional de aprendizagem e, como consequência, deve ser acompanhada de mudanças também na atitude discente frente ao aprendizado. No Quadro 1 as diferenças entre as vivências de aprendizagem na perspectiva tradicional e andragógica são sintetizadas:

Quadro 1 - Diferença entre vivências de aprendizagem tradicional e andragógica

\begin{tabular}{|c|c|c|}
\hline Campo & $\begin{array}{c}\text { Vivência } \\
\text { tradicional }\end{array}$ & Vivência andragógica \\
\hline $\begin{array}{c}\text { Temática } \\
\text { estudada }\end{array}$ & $\begin{array}{c}\text { Apresentada pelo } \\
\text { professor, a partir } \\
\text { de exposições. } \\
\text { Fato dado. }\end{array}$ & $\begin{array}{c}\text { Ganha vida através de } \\
\text { questionamentos que são } \\
\text { compartilhados com os } \\
\text { estudantes, ou nascidos deles, } \\
\text { devem motivar a construção do } \\
\text { aprendizado. }\end{array}$ \\
\hline Conteúdo & $\begin{array}{c}\text { Está presente } \\
\text { nos materiais } \\
\text { didáticos } \\
\text { utilizados na } \\
\text { aula, sendo de } \\
\text { competência do } \\
\text { professor. }\end{array}$ & $\begin{array}{c}\text { É discutido em sala, } \\
\text { considerando a relação entre } \\
\text { o questionamento inicial, a } \\
\text { vivência prévia do estudante } \\
\text { e o que está sendo utilizado } \\
\text { na aula, trazido tanto pelo } \\
\text { professor, quanto pelos } \\
\text { estudantes. }\end{array}$ \\
\hline
\end{tabular}

3 Segundo Nogueira (2004), o termo Andragogia foi empregado pela primeira vez por Knowles, em 1968, em um texto intitulado Adult leadership. E, apesar do termo em grego estar associado à ideia de homem, enquanto gênero, Knowles faz uso do termo sem a associação com gênero, mas com a ideia de ser humano. 


\begin{tabular}{|c|c|c|}
\hline Campo & $\begin{array}{l}\text { Vivência } \\
\text { tradicional }\end{array}$ & Vivência andragógica \\
\hline Aprendiz & $\begin{array}{l}\text { É o típico aluno. } \\
\text { Aquele que } \\
\text { acessa a sala para } \\
\text { aprender, a partir } \\
\text { do que professor } \\
\text { está preparado } \\
\text { para ensinar. }\end{array}$ & $\begin{array}{c}\text { É o estudante. Tem uma relação } \\
\text { com o professor, no entanto, } \\
\text { sabe que é, e se reconhece } \\
\text { como protagonista de seu } \\
\text { aprendizado. Bebe de outras } \\
\text { fontes para que em relação com } \\
\text { o seu conhecimento prévio, } \\
\text { possa elaborar, construir e } \\
\text { reelaborar seu aprendizado e } \\
\text { seus saberes. }\end{array}$ \\
\hline $\begin{array}{l}\text { Sala de } \\
\text { aula }\end{array}$ & $\begin{array}{l}\text { Espaço de saber } \\
\text { transmitido. }\end{array}$ & $\begin{array}{l}\text { Espaço de saber compartilhado } \\
\text { e construído. }\end{array}$ \\
\hline Avaliação & $\begin{array}{l}\text { Testagem de } \\
\text { conhecimentos } \\
\text { do aluno, } \\
\text { aplicada pelo } \\
\text { professor. }\end{array}$ & $\begin{array}{c}\text { Análise acerca do que se } \\
\text { construiu em torno de uma } \\
\text { temática, envolvendo a sua } \\
\text { aplicação e a reflexão sobre a } \\
\text { mesma, a partir das percepções } \\
\text { dos dois atores: professor e } \\
\text { estudante. }\end{array}$ \\
\hline
\end{tabular}

Fonte: Dados da pesquisa.

A partir dessas considerações, como conceber a avaliação nesse contexto? Qual o papel da vivência andragógica de aprendizagem nos processos de ensino e de aprendizagem?

Vale ressaltar, para iniciar a discussão, alguns conceitos sobre avaliação. No entanto, antes, parece ser interessante registrar a etimologia do termo avaliar. Avaliar, vem do latim $a+$ valere e significa dar valor a algo. $\mathrm{O}$ ato de avaliar, portanto, é prática comum na vida do ser humano, que vive a avaliação do momento que acorda, ao momento que vai dormir; e no seu processo de formação, a avaliação se faz presente de diferentes formas: a escolha do curso a frequentar, a escolha dos autores a serem estudados e seguidos, a escolha do que deve ser contestado. Para cada uma dessas ações, uma avaliação prévia se faz necessário, e as escolhas feitas dizem muito sobre quem o indivíduo é onde quer chegar. Assim, homens e mulheres encaram com naturalidade o exercício de avaliar. No entanto, ao ser avaliado, surge a apreensão pelo fato de ser julgado, em especial, se essa avaliação estiver associada à aprendizagem.

O processo de ensino, que segue a proposta andragógica, pretende transformar a experiência de aprendizagem. No entanto, ter como foco inicial os interesses do estudante, para que a partir daí sejam organizados os encontros de estudo, faz com que essa vivência em sistemas formais de educação, seja dificultada, em especial, ao se considerar que nos cursos superiores oficiais existe um conjunto de diretrizes curriculares a serem seguidas. Vale pontuar que um dos fatores motivadores da aprendizagem no Ensino Superior destacada na pesquisa de Sogunro (2015) é a qualidade do currículo, que deve inicialmente ser expressa no plano de curso, com objetivos e metas bem definidos, porque as expectativas criadas pelos estudantes possam ser vivenciadas na concretização desse plano.

Diante desse contexto, talvez a ação mais acertada em termos do Ensino da Educação Superior, seja agregar as práticas da andragogia, - tais como o respeito e utilização do conhecimento prévio do estudante, a prática efetiva da relação entre conteúdo e competências - com a proposta de avaliação da aprendizagem.

Considerando a avaliação e a proposta acima, alguns apontamentos podem ser elencados, na proposta de ação. Assim, seguindo uma inspiração da andragogia e a determinação legal de que, no Brasil, o ato de avaliar precisa ser continuado.

Nesse sentido, apresenta-se uma proposta de avaliação por fases, composta por um conjunto de momentos/atividades, que podem ser assim elencados:

1. No primeiro encontro com o professor, após o estudante demonstrar o seu conhecimento sobre o assunto, e o professor tê-lo trabalhado junto ao grupo, o estudante passaria pelo primeiro momento de avaliação sobre o tema. Aqui, o professor escolheria o instrumento que poderia ser desde uma apresentação feita pelo aluno, através de um texto, algo oral ou ainda a resolução de um problema associado à temática estudada, demarcando o que ele pensava sobre o tema antes da aula, ou do conjunto de aulas, e o que ele pensa naquele momento. Passado esse momento, tem-se o primeiro feedback;

2. A partir do feedback, entre as aulas, o estudante iria identificar e apresentar os conceitos ou técnicas que foram apreendidos e discutidos com o professor. Mais uma vez, ao professor cabe escolher os instrumentos que irá utilizar. Pode ser o retorno ao problema inicial, para análise do refinamento dos conceitos; pode ser um novo problema, desde que o estudante aplique os conhecimentos adquiridos e demonstre o desenvolvimento das competências a ele relacionadas;

3. Com a "finalização" dos estudos sobre um tema se tem a possibilidade de aplicação dos conceitos e técnicas, associados a uma vivência profissional. Aqui, o foco da avaliação seria a vivência das competências e atitudes necessárias para a resolução do problema apresentado, que pode, por exemplo, gerar um produto de aprendizagem. Um novo feedback é dado;

4. Por fim, se teria o momento da autoavaliação do estudante relacionada ao resultado, seguida da avaliação do professor com base no relato do estudante, realizado através dessa linha de avaliação continuada.

5. Com esse trajeto, a prova final não seria um dos instrumentos de avaliação.

O professor avaliaria a autoavaliação do estudante, tendo como base o caminho avançado com os feedbacks, objetivos e metas alinhados no começo do ciclo de aprendizagem e de avaliação, ao mesmo tempo que acompanharia cada etapa da avaliação continuada, ajustando-a através dos feedbacks.

\subsection{Metodologia}

A investigação que subsidia este artigo é de cunho qualitativo, caracteriza-se como sendo pesquisa bibliográfica e utilizou publicações internacionais, de 2015 a 2020, em língua inglesa, disponibilizadas no Repositório de Periódicos da Coordenação de Aperfeiçoamento de Pessoal de Nível Superior (CAPES/MEC).

A busca foi empreendida entre abril e maio de 2020 e os dados foram coletados utilizando como critério de seleção dos artigos o descritor (palavra-chave) "Andragogy" AND 
"University education". Foram identificados 692 artigos. A partir desse corpus inicial de dados foi realizada a seleção dos artigos relativos à Avaliação. Foram desprezados 21 artigos pela impossibilidade de localização do texto completo, restando 671 textos, os quais foram classificados e como resultado foram identificados 96 artigos relativos ao Eixo temático Avaliação.

O corpus de dados foi organizado em planilha excel, seguindo o modelo indicado por Hayashi e Hayashi (2011), contendo as seguintes variáveis: área do conhecimento, país, ano de publicação, link da publicação, Instituição, título, breve resumo, nível, palavras-chave, método de pesquisa, fundamentação teórica, conclusão, tipo de pesquisa. $\mathrm{Na}$ sequência, os resumos foram lidos e, então, identificadas as variáveis citadas. A seguir, 35 dos artigos foram excluídos, alguns deles por não serem escritos em língua inglesa, outros por não se referirem a pesquisas (editoriais, prefácios, práticas de ensino, relatórios de projetos etc.) ou por não estarem alinhados à avaliação de aprendizagem ou à avaliação de programas de ensino.

Como resultado, 61 artigos do total dos 96 selecionados, foram lidos e algumas das ideias encontradas se apresentam como reflexões sobre a temática, na discussão a seguir.

\subsection{Discussão}

Dependendo do contexto em que é utilizada, a palavra "avaliar" pode adquirir diferentes sentidos. Em uma rápida busca em um dicionário, pode-se encontrar "determinar a valia ou o valor de"; "apreciar ou estimar o merecimento de"; "calcular, computar"; "fazer ideia de; supor"; "reconhecer a grandeza, a intensidade, a força de"; "fazer a avaliação de"; "determinar a valia ou o valor, o preço, o merecimento, etc.; calcular, estimar"; "fazer a apreciação; ajuizar" (FERREIRA, 1999, p.238).

Quando se refere a uma avaliação educacional, o que vem à cabeça de todos é uma prova. Invariavelmente, todos que passaram por um sistema formal de ensino relacionam avaliação às provas. No entanto, a avaliação, em qualquer nível de ensino, vai muito além das provas. E é esse sentido mais amplo de avaliação como um processo que pode, em diferentes momentos, assumir diferentes funções. Neste estudo, a avaliação é compreendida como parte do processo de ensino e de aprendizagem.

A avaliação não é um terreno completamente conhecido para quem quer que seja. As suas características, fundamentos e possíveis ações de implementação são temas de pesquisas, principalmente, relacionadas ao universo escolar, que vai da Educação Infantil até o mais alto nível de ensino, adquirindo particularidades em cada um desses. As particularidades relacionadas ao Ensino Superior, que interessam e se referem ao tema deste estudo.

\subsubsection{Avaliação na Educação Superior}

Em todos os segmentos de ensino, a avaliação encontra desafios específicos a cada um desses. Seja com a função de medir o rendimento dos estudantes, diagnosticar dificuldades ou intervir e ajustar o processo de ensino e aprendizagem, a avaliação é sempre um desafio a ser considerado.

$\mathrm{Na}$ avaliação de jovens e adultos se deve respeitar as particularidades desses estudantes. Nesse sentido, entendese que a avaliação nessa faixa etária deve estar sob uma perspectiva andragógica, ou seja, deve ser uma avaliação pensada e planejada para esse público.

Segundo Fida e Shamim (2016, p.181):

A frase comumente ouvida avaliação impulsiona o aprendizado refere-se ao fenômeno pelo qual os alunos tendem a aprender de maneiras que são influenciadas ou determinadas pelo modo como sua avaliação é planejada e implementada.

Nesse sentido, surge uma pergunta: tendo como objetivo esse impulsionar da aprendizagem, quais características deve ter uma avaliação voltada para estudantes da Educação Superior?

Diferentemente das crianças, em que a escola busca a autonomia e a tomada de decisão, já é esperado, socialmente, que os adultos sejam autônomos em suas tarefas do cotidiano, especialmente as profissionais, e que tomem as suas próprias decisões. Portanto, não faz sentido ignorar essa autonomia que os adultos já têm e ensiná-los como crianças. Adultos devem ser tratados e ensinados como adultos.

Tendo vivenciado a vida e formado conhecimento a partir de suas experiências, os alunos adultos têm um conceito de si mesmos como alunos e estão motivados a fazer o que é necessário para atingir seus objetivos. Segue-se que ensinar adultos da mesma maneira que as crianças são ensinadas é repetitivo, na melhor das hipóteses, ou, na pior, contraditório, confuso ou entediante (HARROP; CASEY; SHELTON, 2018, p.130).

As experiências dos alunos adultos devem ser levadas em consideração e a eles deve ser dada a chance de estabelecer relações entre as experiências pessoais anteriores e as novas experiências proporcionadas pela aprendizagem no curso. A aprendizagem experiencial faz todo sentido em um universo, em que os estudantes tomam decisões diariamente, sejam em seus empregos, com suas famílias, ou qualquer outra atividade cotidiana.

Com a grande facilidade ao acesso às informações, principalmente, por dispositivos digitais, outra característica importante da avaliação em uma abordagem andragógica de ensino, é como os alunos buscam, filtram e tratam as informações. Pois, todos os dias, os estudantes são expostos a todo tipo de informações, das mais plausíveis às mais absurdas, e por muitos meios de comunicação.

As teorias de aprendizagem andragógicas enfatizam as experiências fundamentais, os autoconceitos e as motivações dos alunos, atraindo os alunos imediatamente para a experiência de aprendizagem, para que a sala de aula se torne mais sobre o envolvimento ativo do aluno no processo de aprendizagem, em vez de meramente receber informações. $\mathrm{O}$ aprendizado andragógico é centrado no problema, e não no 
conteúdo, um princípio fundamental que se alinha de forma eficaz com a nova era do Google de informações infinitas que exige pensamento crítico, autoconsciência e intencionalidade (HARROP; CASEY; SHELTON, 2018, p. 131, tradução nossa).

Portanto, a avaliação deve ser mais sobre como os alunos buscam fontes de informação, como as utilizam para fundamentar suas decisões e resolver os problemas em questão, do que se eles as memorizam. A memorização não deve ser completamente descartada, mas a ênfase na memorização deve ser diminuída para informações que não possam ser buscadas, imediatamente, em um dispositivo qualquer.

A Avaliação sob o olhar andragógico respeita os conhecimentos anteriores dos alunos, aprendidos dentro ou fora do curso de formação que estão inseridos. Nessa perspectiva, o que acontece em sala de aula não se refere à formação, mas, sim, a um de seus complementos, pois o aluno adulto está inserido em vários ambientes formais e informais, em que pode aprender. Os conteúdos apreendidos, então, complementam a formação profissional do indivíduo, ou seja, a formação de cada aluno é única, pois leva em consideração suas aprendizagens anteriores ao curso.

Outra característica a ser considerada na educação de adultos é a autoavaliação. A autoavaliação é importante para a tomada de consciência e faz parte da formação profissional. Saber se autoavaliar é o primeiro passo para ser mais autônomo e é uma característica desejada no mundo do trabalho. Para que o estudante se autoavalie, é preciso que lhe sejam dadas condições para que isso aconteça. Os objetivos de aprendizagem precisam estar claros e, se possível, devem ser elaborados em conjunto, levando em consideração as intenções de ensino e as demandas do mundo do trabalho. Como é impossível prever e aprender tudo o que será necessário ao seu futuro profissional, aprender a se autoavaliar, identificar suas deficiências e qualidades, e como suprir essas deficiências e potencializar as qualidades, construindo o próprio itinerário de aprendizagem ao longo de toda a vida, torna-se essencial para o sucesso profissional.

\subsubsection{Os instrumentos de avaliação}

Como fazer a avaliação também deve ser objeto de reflexão. Os instrumentos devem ser coerentes com as intenções que se tem com a avaliação. Nesse sentido, alguns instrumentos ganham destaque na perspectiva de formação. Como o Ensino Superior tem a intenção de formação de um profissional, a avaliação deve refletir essa intenção.

Destaca-se aqui a utilização do portfólio avaliativo. O portfólio pode ser entendido como uma coleção de alguns ou de todos os registros das atividades realizadas pelos estudantes no curso. É importante frisar que o portfólio avaliativo vai além da simples documentação das atividades. Para que tenha o efeito desejado, é preciso que mais do que a documentação, os alunos reflitam a respeito das atividades realizadas, do porquê realizaram as atividades, que tipo de conhecimento as atividades proporcionaram e quais deficiências de aprendizado elas apontaram. Portanto, portfólio avaliativo exige do aluno uma atividade desejada de reflexão e autoavaliação.

A utilização de portfólio para avaliação traz consigo a perspectiva de avaliação individualizada, pois cada portfólio é único e produzido pelo próprio estudante, portanto, influenciado pelas suas experiências e pelo seu conhecimento individual.

Cada estudante deve fazer em seu portfólio as suas análises críticas e observações. Essas análises e observações servem para o professor como feedback da sua aula e das atividades propostas.

Além disso, como uma ferramenta de avaliação, os portfólios podem ser de base ampla, englobando materiais que são formativos e somativos, qualitativos e quantitativos, bem como considerados altamente individualizados (FIDA; SHAMIM. 2016, p. 182, tradução nossa).

Segundo Fida e Shamim (2016), o portfólio se revela, em especial, um bom instrumento para estudantes de medicina, pois incentiva reflexão da própria prática e incentiva a independência dos estudantes em seus estudos.

Os benefícios do portfólio; entretanto, não se limitam ao aprendizado do aluno. O feedback dos alunos sobre o processo de aprendizagem fornece aos educadores uma base sobre a qual refletem e melhoram seus métodos de ensino e seus métodos de cumprimento de suas responsabilidades profissionais. Esse processo pode melhorar as relações aluno-professor e fornecer suporte aos alunos enquanto eles enfrentam os desafios pessoais, emocionais e educacionais de concluir sua educação médica (FIDA; SHAMIM. 2016, p. 182, tradução nossa).

Os portfólios eletrônicos ou e-portfólios são caracterizados por serem realizados utilizando um recurso digital. Os e-portfólios têm todas as vantagens do portfólio tradicional e ainda possui a vantagem adicional de ser possível o acompanhamento por parte do professor, sem a necessidade de que os alunos entreguem cópias físicas e, assim, esse instrumento de avaliação ganha tempo e possibilita que o instrumento seja também aplicado em outras modalidades de ensino que não a presencial. A dificuldade de utilização de portfólios eletrônicos está normalmente relacionada à dificuldade de utilização das tecnologias digitais em sala de aula (presenciais ou não) assim, segundo Sharifi, Soleimani e Jafarigohar (2016), os professores precisam ser apoiados pela equipe pedagógica, enquanto aprendem a utilizar as novas tecnologias para ensinar.

\subsubsection{As conceituações e práticas associadas ao Feedback}

Um dos instrumentos sinalizados que colabora para se ter a avaliação com essas características são os feedbacks em intervalos regulares e ciência do aluno frente aos critérios utilizados no processo avaliativo antes de sua realização. Consequentemente, tem-se que essas características definem as expectativas que são estabelecidas sobre os alunos, possibilitando que eles possam se programar, oportunizando 
momentos de monitoramento, ensaio e prática. Por outro lado, todo o processo de avaliação deve ser composto por procedimentos que possibilitam ao aluno esse tipo de desenvolvimento, o que denota a necessidade de coerência entre os objetivos de aprendizagem do currículo, os instrumentos de avaliação e a intencionalidade da instituição frente a esses elementos.

Dejene (2019) identificou que os professores, excessivamente, usam questionários como instrumentos de avaliação, o que levou o autor a afirmar que a avaliação contínua foi reduzida a teste contínuo. Foi também identificado que nem sempre os alunos recebem feedback dos processos de avaliação, aos quais são submetidos e muitos professores se justificam pelo fato de não conseguirem individualizar o feedback diante da quantidade de alunos, que atendem em sala de aula. Em relação aos critérios de avaliação, os alunos demonstram desconhecê-los o que inviabiliza afirmar que, no contexto da pesquisa, configura-se um processo de avaliação contínua dos estudantes.

A investigação realizada por Ettien, N'Guessan e N' Guetta (2017) teve por objetivo analisar os conhecimentos prévios mobilizados por instrutores na avaliação de adultos. Os autores consideram os feedbacks um integrante do processo de avaliação, que pode fornecer aos alunos e professores informações a respeito dos processos de ensino e de aprendizagem, de modo que o professor pode se valer dessas informações para modificar a forma como atua e, consequentemente, a aula que propõe aos alunos. Por outro lado, os autores apresentam em três momentos do texto que o uso de feedbacks se refere a uma das características da avaliação formativa e reforçam que essa prática apresenta contribuições para ter noção sobre os processos de ensino e de aprendizagem, bem como do planejamento curricular. Cabe destacar que esses autores associam ao feedback a noção de diagnóstico, pois com esse instrumento se pode diagnosticar os pontos falhos, intervir e monitorar a aprendizagem.

A investigação conduzida por Reirson et al. (2017), desenvolvida no contexto da área da saúde, na formação de enfermeiros, tomou as seções debriefing como objeto de análise. Essa estratégia parte de situações práticas, via processo de simulações. Em suma, o foco é destinado à resolução de problemas, gestão, orientação e reorientação do desempenho em várias situações. De acordo com os autores, o debriefing se estrutura nos seguintes elementos: reflexão, feedback, desenvolvimento de conhecimento e segurança psicológica.

Nesse contexto, o feedback é considerado parte integrante do processo de simulação, de modo que contribui para a aprendizagem dos participantes. $O$ feedback pode ser confundido com o conceito de debriefing ${ }^{4}$, mas são processos distintos, pois o feedback, no contexto do artigo, apresenta a característica de ser uma forma unilateral sobre o desempenho, comportamento e aprendizagens dos alunos, com o intuito de refinar a prática por meio do desenvolvimento de habilidades.

Os dados analisados por Reirson et al. (2017), referem-se a 12 seções de debriefing realizadas em 2013 e 11 realizadas em 2014. Os autores identificaram que a amplitude dos feedbacks foi distinta nos anos analisados, o que acarretou diferenças na maneira como os processos de ensino e de aprendizagem se configuraram. Em 2013, os feedbacks tiveram a característica de serem mais específicos, o que possibilitou aos alunos um avanço no processo de debriefing, pois eles puderam comentar sobre o seu aprendizado, possibilitando, também, um novo feedback para os professores, que possibilitou pensar a respeito das práticas realizadas. Em 2014, os feedbacks foram mais abrangentes e precisos, comparados com os de 2013, sendo mais coerentes com a proposta de ensino para adultos, permitindo aos alunos realizarem a autogestão do seu conhecimento em um processo de aprendizagem mais autônomo.

Os autores também destacam que as mudanças compreendidas, entre 2013 e 2014, possibilitaram que rapidamente os participantes pudessem refletir sobre os cuidados em si e compartilharam via feedbacks específicos e abrangentes. Por outro lado, os professores construíram um espaço reflexivo para que a prática em discussão pudesse ser tomada como objeto de análise, indo ao encontro do que se espera para um ambiente de aprendizagem experiencial para o adulto.

A pesquisa apresentada por Washburn et al. (2016) também se situa na área da saúde e teve por objetivo analisar a viabilidade e aceitabilidade da utilização de simulações virtuais em pacientes em um contexto interdisciplinar. Diferente dos demais artigos, o conceito de feedback se apresenta associado à prática utilizada com as simulações virtuais, de modo que a associação de ambos se coloca pertinente para a busca de melhorias nos processos de ensino e de aprendizagem e, consequentemente, a formação da habilidade médica. Outro ponto salientado no artigo diz respeito ao momento oportuno em que o feedback se coloca mediado pelas simulações virtuais. Nesse sentido, os autores ressaltam que os alunos podem realizar simulações por diversas vezes, de modo a parar, retroceder e continuar, o que possibilita aos instrutores e aos alunos, em grupo, elaborar feedbacks cada vez mais específicos, aprimorando a habilidade médica.

Cross e Palese (2015) realizaram uma investigação com cinco tutores de Matemática com o intuito de testar o impacto do debate em fóruns de discussão, para isso, desenvolveram uma comparação entre fóruns em que se adotou a avaliação em uma perspectiva formativa e outros que não. A investigação assume a avaliação em uma perspectiva formativa e para isso se vale dos CAT - Classroom Assessment Techniques - que,

4 Cabe destacar que no contexto do Ensino de Medicina essa informação não se aplica. 
em uma tradução livre do termo, referem-se às técnicas de avaliação para a sala de aula. De um modo geral, os CAT são instrumentos para a avaliação formativa se referem às questões não graduadas e realizadas pelos alunos, em sala de aula, mas no contexto desta pesquisa foi no ambiente virtual de aprendizagem. Com esse instrumento, o professor ou tutor pode, por meio da análise das respostas dos alunos, isolar estratégias, modos mobilizados pelos alunos para resolver a questão e intervir diretamente nas falhas diagnosticadas.

De acordo com os autores, a utilização das CAT contribui para que se possa dar aos alunos uma atenção mais individualizada, especificadamente, no que se refere à estrutura em que são elaborados os questionamentos, bem como as técnicas utilizadas na resolução de problemas, levando o tutor e o aluno a estabelecerem uma interação mais acirrada e de maior frequência no ambiente virtual. É nesse contexto que os feedbacks surgem, pois os tutores são levados constantemente a interagir com os alunos. Por outro lado, os CAT podem se configurar como um guia para diagnóstico e intervenção em situações, nas quais os alunos apresentem mais dificuldades. Concluem os autores que os CAT permitem uma classificação das respostas dos alunos, de forma rápida, possibilitando uma triagem de intervenções e os feedbacks se colocam nesse contexto como veículo entre o tutor e o aluno.

Os autores concluíram que as atividades online, fundamentadas nos CAT, contribuíram para a individualização dos processos de ensino e de aprendizagem e possibilitaram a realização de feedbacks mais pontuais, em uma maior frequência, o que acarretou uma intervenção mais intensa no processo de aprendizagem.

A pesquisa realizada por Sogunro (2015) teve por objetivo conhecer os fatores, que motivam e sustentam os adultos, nos processos de ensino e de aprendizagem. A pesquisa contou com a participação de duzentos e três estudantes universitários, chegando à conclusão de que são oito os fatores que motivam o adulto: mediação de qualidade; currículo; os conhecimentos devem ser relevantes, apresentado um caráter mais pragmático; salas de aula interativas e eficazes, que promovem práticas de gerenciamento; avaliação progressiva e feedback oportuno; autodirecionamento; meio ambiente propício para a aprendizagem e práticas de aconselhamento. De acordo com o autor, esses fatores são de extrema importância para que o adulto possa se manter engajado no processo de aprendizagem, aumentando a sua força de vontade em estudar, visando oportunizar uma aprendizagem com mais qualidade no contexto do Ensino Superior.

Nesse contexto, feedback se coloca como um aliado para a avaliação progressiva, configurando-se como um dos fatores que contribuem para que o aluno adulto se sinta motivado. Os dados analisados, pelo autor, mostram que a avaliação progressiva é contínua e visa refletir o desempenho do aluno ao longo do processo de aprendizagem. Todavia, quando se alinha a feedbacks rápidos e que façam sentido para o aluno, tende a ampliar as potencialidades formativas das tarefas realizadas. Noventa por cento dos entrevistados pelo autor ressaltaram que a aplicação de um número intercalado de instrumentos de avaliação, seguido de feedbacks rápidos e que sejam oportunos, no sentido de possibilitar para o aluno clareza sobre seu desempenho e formas de refiná-lo, melhorando cada vez mais. Dessa forma, os feedbacks são compreendidos como uma parte do processo de aprendizagem.

Na continuidade, o autor aprofundou a compreensão sobre as relações estabelecidas entre os feedbacks e o processo de motivação e de engajamento do aluno adulto. Fundamentando-se em Toohey (1999), compreende-se que os alunos adultos são motivados quando as tarefas e os instrumentos de avaliação são estruturados e sequenciados de forma que ele tenha clareza a respeito dos critérios utilizados no processo de avaliação, bem como os tipos de feedback que serão utilizados.

Outra afirmação levantada pelo autor diz respeito ao fato de o feedback proporcionar aos alunos condições para se colocaram como juízes do seu próprio progresso e desempenho, pois todos os participantes da pesquisa ressaltaram que, quando o feedback é oportuno, se tem um grande impacto motivador, contribuindo para melhoria na qualidade da aprendizagem. Para expressar com mais clareza, o autor elabora o ciclo do feedback (Figura 1).

Figura 1 - Ciclo do Feedback

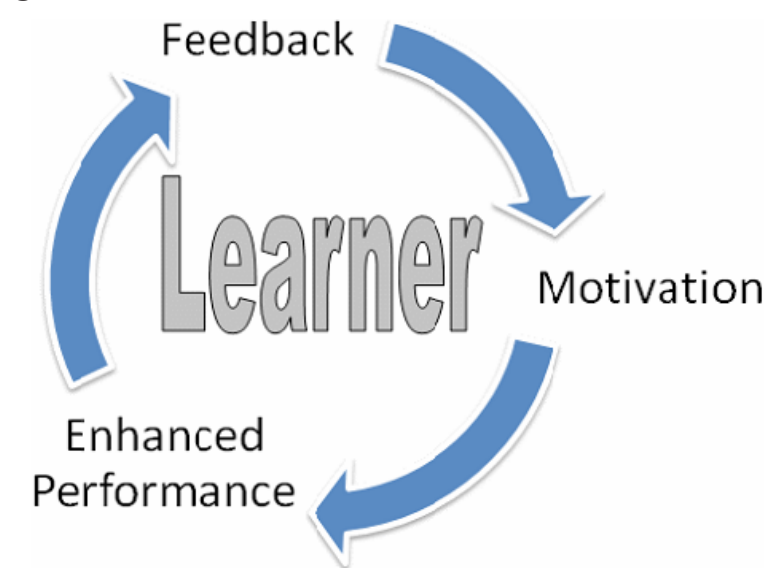

Fonte: Sogunro (2015, p.31).

De acordo com a figura, o ciclo do feedback é caracterizado como um processo interativo, composto por três estágios: feedback, motivação, melhoria na aprendizagem e desempenho do aluno. Pode-se interpretar que uma ação incide na outra, de modo que o ciclo começa e termina com o feedback, ou seja, o aperfeiçoamento no desempenho e melhoria da aprendizagem advém da motivação que é despertada pelo feedback. Porém, o ciclo não se encerra no desempenho melhorado, pois há evocação de um novo feedback, que alimenta o ciclo em um processo contínuo de aprendizagem.

O autor também comenta sobre a maneira como o feedback para o aluno adulto deve ser elaborado, visando transparecer honestidade e respeito, em um tom de diplomacia, pois é comum que o aluno adulto se sinta mal, desmoralizado, 
frente a um feedback mais incisivo e, consequentemente, possa perder o interesse e motivação de se manter engajado nos processos de ensino e de aprendizagem. Diante desse fato, o autor retoma a ideia de que o aluno adulto deve ter ciência do que se espera dele no processo de aprendizagem, quais os critérios de avaliação e instrumentos que serão utilizados, ou seja, quanto mais o adulto tiver conhecimento do currículo, dos instrumentos de avaliação, do que se espera dele, enquanto aluno no curso, aliado a feedbacks precisos, que façam sentido para ele e lhe possibilitem refinar práticas e conhecimentos construídos, mais se terá alunos motivados e engajados no processo de aprendizagem.

\section{Conclusão}

A educação, nas diferentes etapas da vida das pessoas, assume objetivos diferentes, a avaliação também compartilha dessas sutilezas de modo que, na Educação Superior, o sistema de avaliação deve ser planejado para o adulto, em um contexto de profissionalização, ou seja, considera-se a formação de um profissional, em que se espera o desenvolvimento de um conjunto de competências e habilidades - perfil do egresso - e a avaliação pode possibilitar o acompanhamento de como esse processo ocorre, bem como fomentá-lo.

Entende-se que muitas das características aqui apontadas como da avaliação de jovens e adultos, ou seja, sob uma perspectiva andragógica, podem também serem características importantes para a educação de crianças. Não se tem aqui a intenção de fazer um contraponto entre a avaliação voltada às crianças e avaliação voltada aos adultos. A intenção é chamar a atenção para as características da avaliação na educação de jovens e adultos, para que sejam respeitadas as particularidades da Educação Superior e a sua avaliação.

Uma característica fundamental que a avaliação precisa considerar é que o aluno adulto já é autônomo, vivencia ou já vivenciou muitas experiências, em várias esferas da sociedade, de modo que apresenta uma bagagem de conhecimentos, que podem ser contemplados e valorizados. Nesse sentido, a formação possibilitada na Educação Superior para o aluno adulto não pode ser compreendida como uma formação isolada, tomando-o como uma tabula rasa, mas como uma suplementação às diversas formações as quais o adulto já vivenciou, especialmente, as relacionadas com o mundo do trabalho.

Dessa forma, os instrumentos de avaliação podem se configurar como oportunidades para que o aluno adulto reflita sobre o seu processo de aprendizagem, relacionando o que sabe com o que será aprendido, bem como o mundo do trabalho ao qual pertence e ao qual aspira pertencer. Os portifólios, especificamente os e-portifólios, podem possibilitar ao aluno adulto essas reflexões, promovendo a autoavaliação e autonomia.

Outro aspecto que a avaliação apresenta, neste contexto, é o fato de promover a motivação e manutenção do engajamento do aluno no processo de aprendizagem e, para isso, assume a característica de ser uma avaliação progressiva, composta por feedbacks oportunos. A avaliação progressiva acompanha todo o processo de aprendizagem do aluno, analisando a maneira como o sujeito se desenvolve frente ao que se espera dele e os feedbacks devem ser oportunos para que os alunos possam se sentir contemplados, de modo que faça sentido para ele e que lhe conduza no processo de aprendizagem.

Analisando as propostas e as experiências vivenciadas nos estudos apresentados, é reforçada a ideia de que, em se tratando da formação de adultos, o exercício de avaliação, ao ser planejado e realizado como um momento do processo de aprendizagem, possibilita não apenas mais engajamento dos estudantes, como também melhor aprendizado. Nessa caminhada, conforme apresentado, conclui-se que alguns aspectos são indispensáveis, a saber: planejamento, compartilhamento dos critérios de avaliação e dos objetivos de aprendizagem e feedbacks. Tratar o aluno adulto realmente como o adulto que é, que traz em si uma carga de conhecimento do mundo, é um desafio a ser enfrentado pelos docentes. No exercício da profissão, a avaliação do adulto, como parte integrante da prática docente, na Educação Superior, é outro importante desafio a ser urgentemente enfrentado.

\section{Referências}

BARRIGA, A.D. Uma polémica em relación al examen. Rev. Iberoam. Educ., n.5, p. 161-181, 1994.

CATANI, D.B. História das práticas de avaliação no Brasil: provas, exames e testes ou a longa provação dos alunos rumo à distinção ou ao "triunfo escolar" (1890-1960). Currículo sem Fronteiras, v. 17, n. 1, p. 8-14,. 2017.

CROSS, T.; PALESE, K. Increasing Learning: Classroom Assessment Techniques in the online Classroom. Am. J. Distance Educ., v.2, n.29, p.98-108. 2015 . doi: 10.1080/08923647.2015.1023594.

DEJENE, W. The practice of modularized curriculum in higher education institution: Active learning and continuous assessment in focus. Cogent Education, v.6, p.1-16. 2019. doi: https://doi.org /10.1080/2331186X.2019.1611052.

ESTEBAN, M.T; (Org.). Avaliação: uma prática em busca de novos sentidos. Rio de Janeiro: DP\&A, 2012.

ETTIEN, A.; N'GUESSAN, A.; N'GUETTA. An appraisal of financial authority trainers' prior-knowledge in adult learning assessment. Bulgarian J. Scie. Educ. Policy, v.11, n.2, p.294-319, 2017.

FERREIRA, A.B.H. Avaliar. Novo Aurélio Século XXI: o dicionário da língua portuguesa.. Rio de Janeiro: Nova Fronteira, 1999, p. 238.

FIDA, N. M.; SHAMIM, M.S. Portfolios in Saudi medical colleges. Why and how? Saudi Med. J., v.37, n. 3, p.179-183, 2016.

HARROP. J.A.; CASEY. R.; SHELTON. M. Knowles, kolb, and google: prior learning assessment as a model for 21 st-century learning. J. Continuing Higher Educ., v.66, p. 129-133, 2018. doi: https://doi.org/10.1080/07377363.2018.1469079

KNOWLES, M.S.; HOLTON E., SWANSON, R. Aprendizagem de resultados: uma abordagem para aumentar a efetividade da educação corporativa. Rio de Janeiro: Elsevier, 2011. 
MOORE, M. G. Flipped classrooms, study centers andragogy and independent learning. Am. J. Distance Educ., v.30, n,2, p.6567, 2016. doi: 10.1080/08923647.2016.1168637.

NOGUEIRA, S. M. Andragogia: que contributos para a prática educativa. Linhas, v.5 n.2, 2004.

PEDROCHI JUNIOR, O. Avaliação como oportunidade de aprendizagem em Matemática. 2012. 56f. Dissertação (Programa de Pós-Graduação em Ensino de Ciências e Educação Matemática) - Universidade Estadual de Londrina, Londrina, 2012.

REIERSON, I. A.; HAUKEDAL, T. A.; HEDEMAN, H.; BJøRK, I. T. Structured debriefing: What difference does it make? Nurse Educ. Practice, n.25, p.104-110, 2017. doi: http://dx.doi. org/10.1016/j.nepr.2017.04.013 Acesso em 09 set 2020

SHARIFI, M.; SOLEIMANI, H.; JAFARIGOHAR, M.
E-portfolio evaluation and vocabulary learning: Moving from pedagogy to andragogy. British J. Educ.Technol., 2016. doi: 10.1111/bjet.12479.

SOGUNRO, O. A. Motivating factors for adult learners in higher education. Int. J. Higher Educ., v.4, p.22-37, 2015.

TOOHEY, S. Designing courses for higher education. Philadelphia: Open University Press, 1999.

WASHBURN, M.; BORDNICK, P.; MPH.; RIZZO, A.S. A pilot feasibility study of virtual patient simulation to enhance social work students' brief mental health assessment skills. Soc. Work Health Care, v.55, 2016. doi: 10.1080/00981389.2016.1210715.

ZABALA, A. A prática educativa: como ensinar. São Paulo: Penso, 2015 